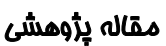

\section{بررسى تاثير سويرمينت (اساذس نعنا) بر شدت درد حين كولونوسكويى كودكان}

\author{
مهرى نجفى'، فرزانه معتمد'، "محمد على كيانى"، على خاكشور"، معصومه سعيدى rاو'، سيد على جعفرى"، بدرام عطايى"، مجيد غيور

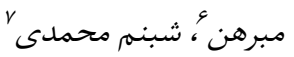

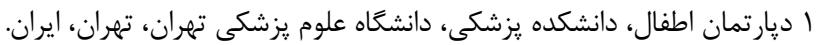

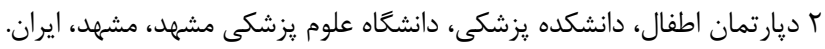

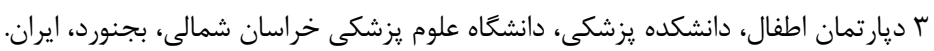

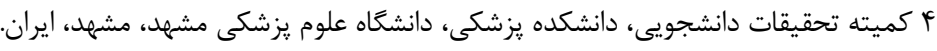

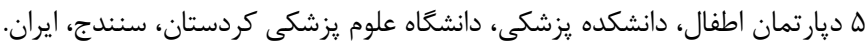

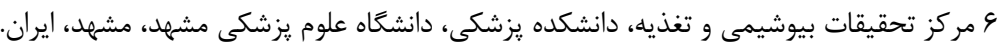

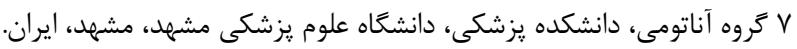

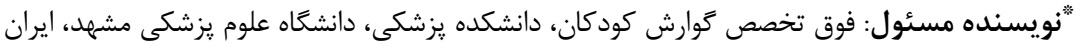
برّت الكترونيك: kianiMD@yahoo.com

جكيده زمينه و هدف: درد در حين عمل كولونوسكويى به ويثه در كودكان از جمله جالش هايى است كه تيم درمانى با آن مواجه هستند. هدف

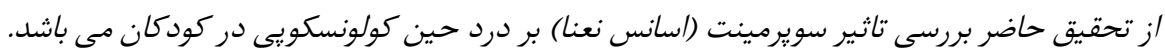

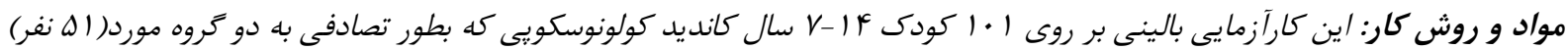

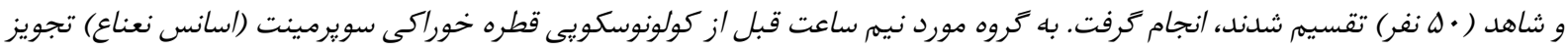

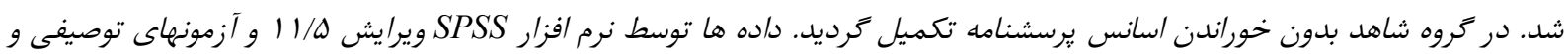

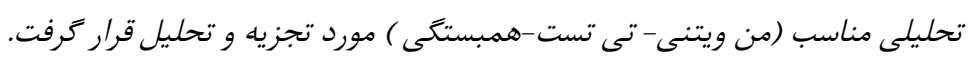

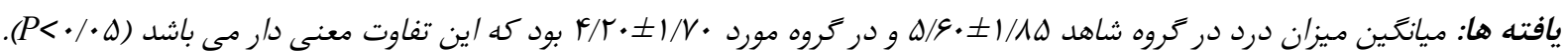

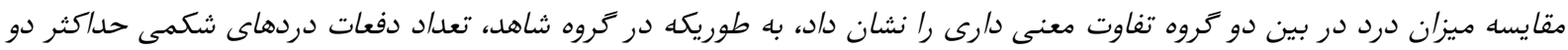

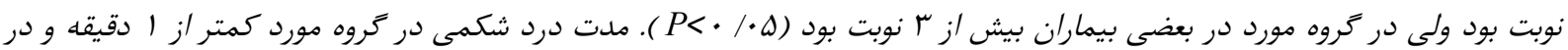

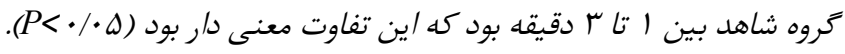

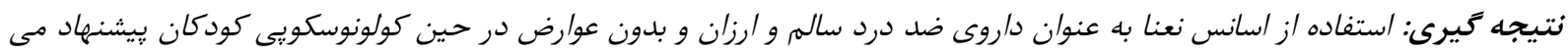

واز ه هاى كليدى: نعناع - درد-كولونوسكويى سويرمينت

مخدرها و ضد التهاب هاى غير استروئيدى، علاوه بر هزينه مقدمه اى كه بر بيمار تحميل مى شود، عوارض جانبى زيادى از از درد يكى از تظاهرات بالينى ناخوشايند است. درد مكانيسم قبيل سركوب سيستم تنفس، تهوع، يوريورا، خونريزى و

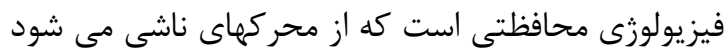

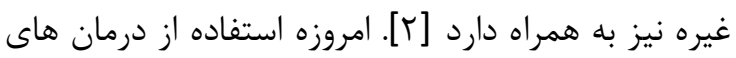
امروزه جهت تسكين درد از روش هاى دارويى و غير

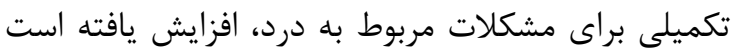

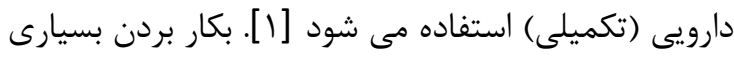

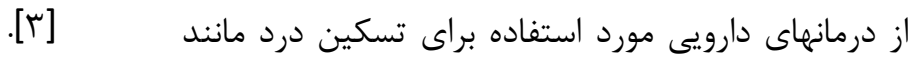


آنها بر روى يكديگر تاثير كذاشته و يا تداخل كند، هر كدام

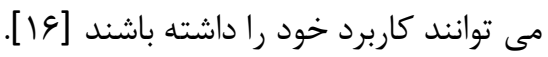
كولونوسكويى روشى براى بررسى روده بزرى است كه

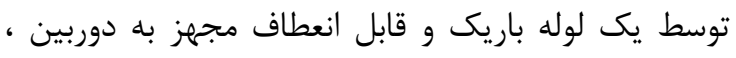

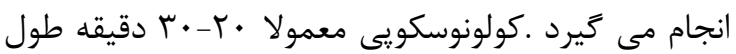
مى كشد كه مى تواند بر اساس يافته يا اعمالى كه انجام

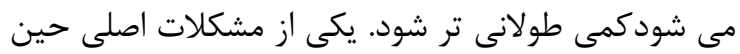

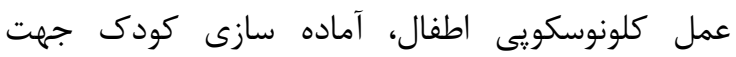
همكارى در عمل كولونوسكويى، رفع ترس و درد كودى

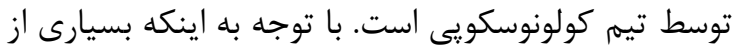
داروهاى ضد اضطراب و ضد درد براى تجويز به اطفال مناسب نيستند و يا نياز به تزريق دارند يعنى همان جيزى

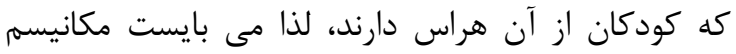

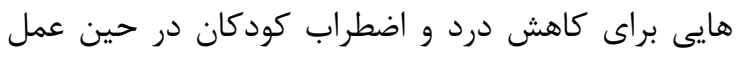
كولونوسكويى آزمايش و مورد تاييد قرار كيرند.در تحقيق حاضر از كياه درمانى جهت كاهش درد استفاده شده است.

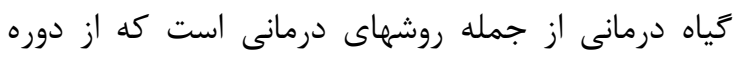

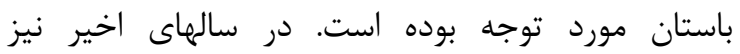
تحقيقات فراوانى در مورد اثرات ضد دردى عصاره گياهان و فراورده هاى كياهى در كشورهاى مختلف صورت كرفته

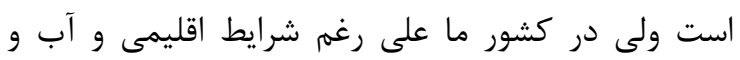
هوايى مناسب براى رويش اين خياهان، تحقيقات اندكى

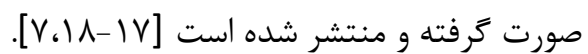

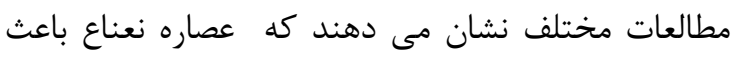
كاهش درد در بيماران مبتلا به سندرم روده تحريك يذير

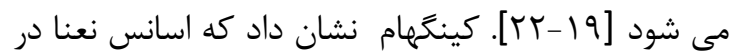
اسياسم كولون موثر است [بr]. هدف از تحقيق حاضر بررسى تاثير تجويز قطره خوراكى استى

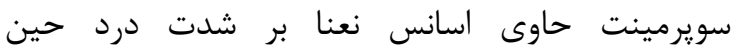

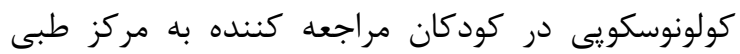
كودكان تهران مى باشد.

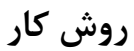

اين مطالعه تجربى در قالب طرح بزوهشى در دانشعاه علوم

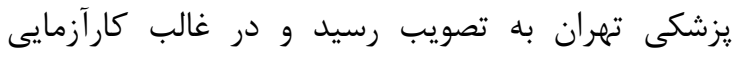

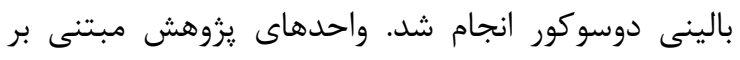

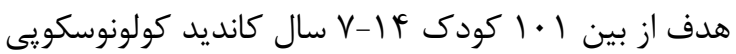
در عماهه دوم سال اوبادر مركز طبى كودكان تهران
خوشبختانه كشور ايران با برخوردارى از شرايط جغرافيايى

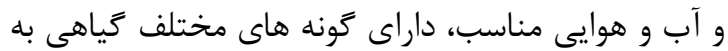

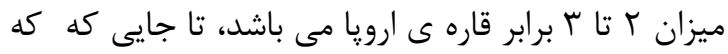

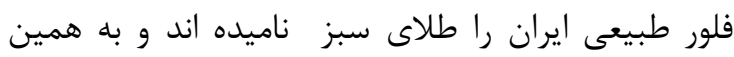

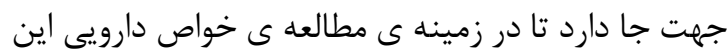

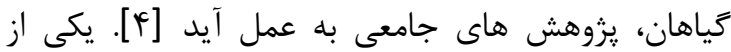
مهمترين كام هاى برداشته شده، ترايش جهانى براى بهائ

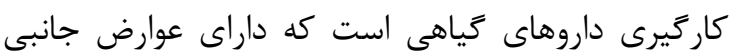

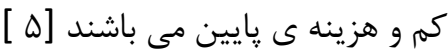

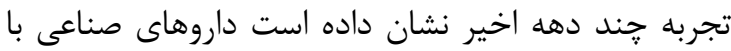
تمام كارايى، اثرات نامطلوب بسيارى را به همراه دارند. به دانه

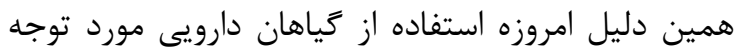

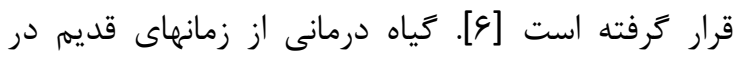

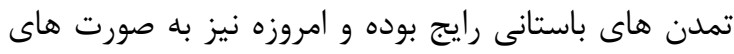
مختلف، اعم از فراورده هاى كياهى يا عصاره هائ تائ تام در

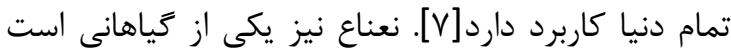

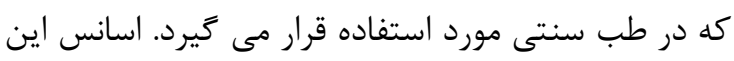

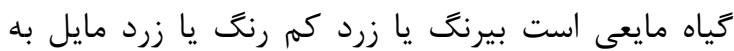

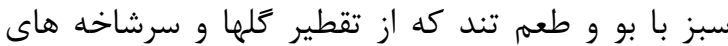
تازه به دست مى آيد و شامل موادى مانند: Volatile oil,Caravone, Limonene, Cineole, Menthol,Menthone,Isomenthone نعناع داراى خواص ضدباكتريايى و ضدقارجى [^]، آنتى

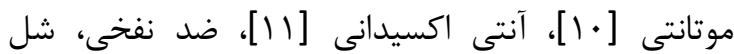

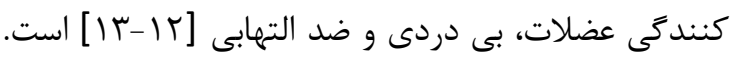
محققان در مطالعات آزمايشگاهى نشان دادند روغن نعنا

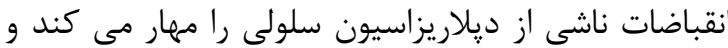
باعث بلوك كانال كلسيم مى شود. همجنين اين كياه

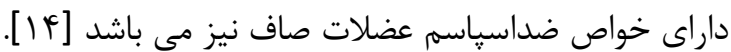
قطره خوراكى سويرمينت داروى جديدى در ايران مى باشد كه از دسته داروئى ضد نفخ هاست، از اسانس كياه نعناع بان

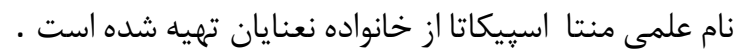
اين فراورده بر اساس وجود حداقل ه/9 ميلى كرم كارون (carvon)

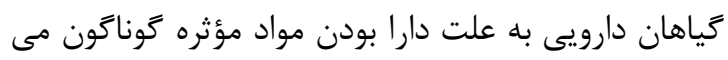

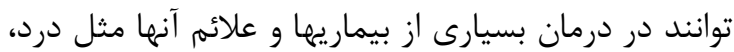
مورد استفاده قرار گيرند بدون آنكه مجموعه مواد مؤثره 
تجزيه و تحليل قرار ترفت. سطح معنى دارى ه •|•>در نظر كرفته شد.

يافته ها ميانگين سنى كودكان در كروه شاهد

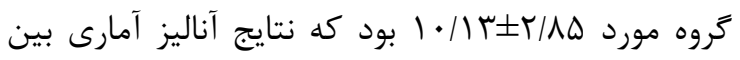

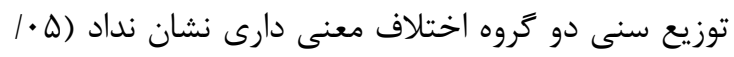

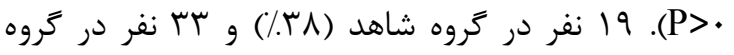

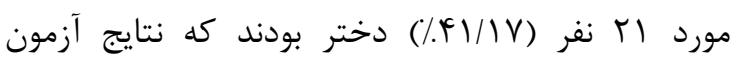
آمارى اختلاف معنى دارى را بين دو گروه نشان نداد

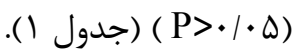

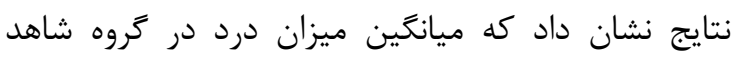

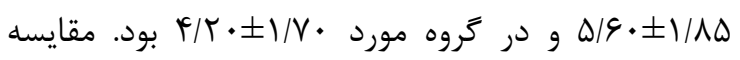

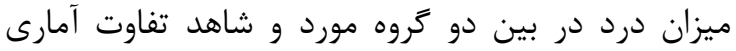

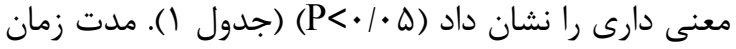

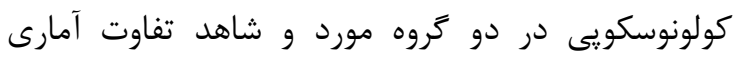
معنى دارى را نشان نداد (جدول Y Y). در كروه شاهد، تعداد دفعات دردهاى شكمى حداكثر دو نوبت بود ولى در كروه

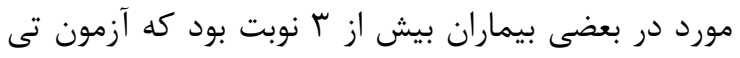

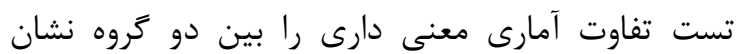

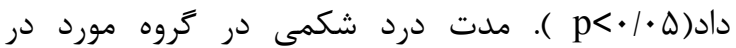

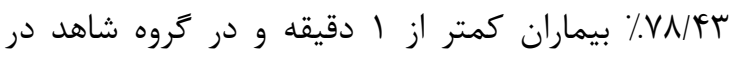

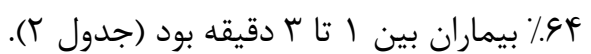

انتخاب و پِ از تكميل رضايت نامه كتبى توسط والدين

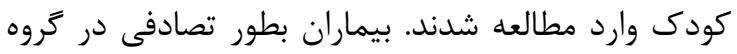
مورد اله نفر و در تروه شاهد •له نفر قرار كرفتند.

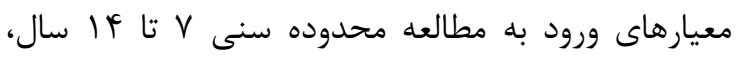
شك به بيماريهاى روده يا يوليٍ و خونريزيهاى نامشخص بود. معيارهاى خروج شامل عدم داشتن سلامت روانى،

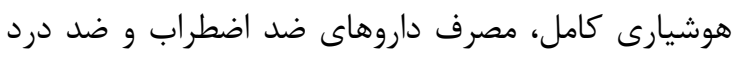
بود. بيماران براساس سن و جنس همسان سازى شده و از نيم ساعت قبل از عمل كولونوسكويى به صورت تصادفى در يكى از دو گروه شاهد و مورد قرار كرفتند.

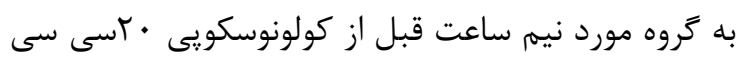

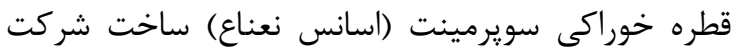
باريج اسانس تجويز شد. بعد از كولونوسكوبى يرسشنامه Pediatric pain questionnaire

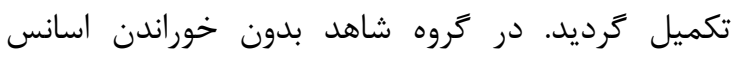

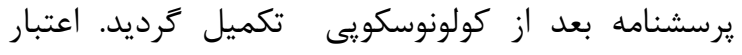

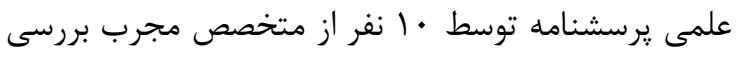

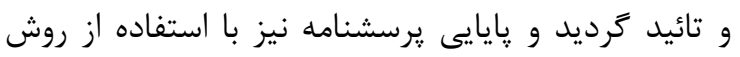

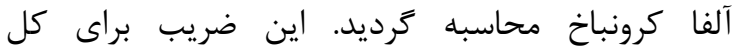

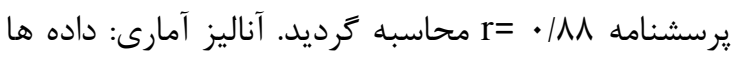

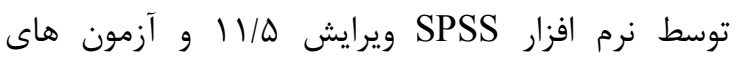
توصيفى و تحليلى (همبستخى -من ويتنى -تى تست) مورد

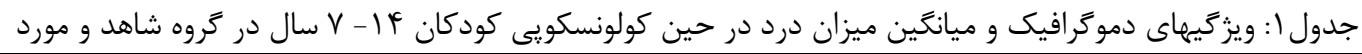

\begin{tabular}{|c|c|c|c|}
\hline pvalue & 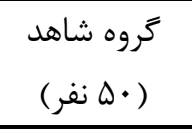 & 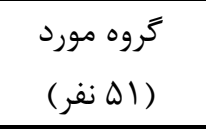 & متغير \\
\hline $\mathrm{P}=\cdot / / \mathrm{T}$ & $q / \wedge \pm r / \Delta \Delta$ & $1 \cdot / 1 r \pm r / \wedge \Delta$ & ميانگَين سن (سال) \\
\hline $\mathrm{P}=\cdot / T_{1}$ & $\%$ \% & $\% q Y / I V$ & جنس دختر (درصد) \\
\hline $\mathrm{P}=\cdot / \cdot 1$ & ${ }^{*} \Delta / \varphi \cdot \pm 1 / \Lambda \Delta$ & $\boldsymbol{c} / \mathrm{r} \cdot \pm 1 / \mathrm{V}$. & ميانگين ميزان درد \\
\hline
\end{tabular}


جدول ז: مدت زمان كلونوسكويى، ميانگين و مدت تعداد دفعات دردهاى شكمى حين كلونسكويى

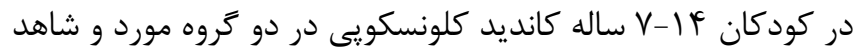

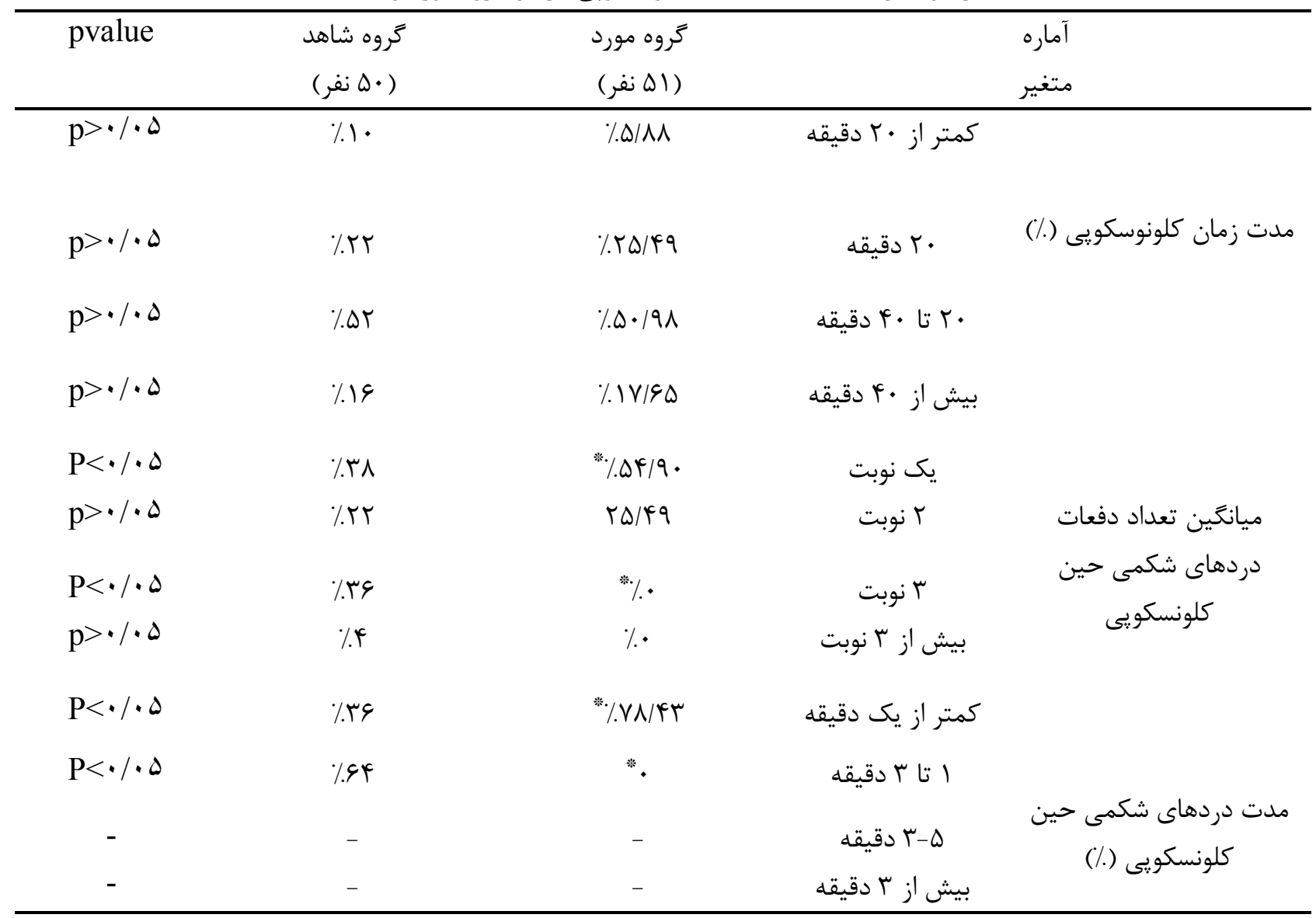

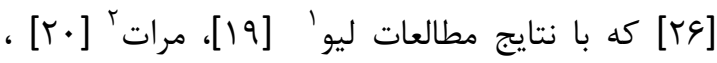

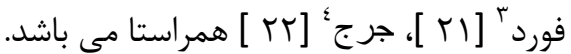
نتايج مطالعه شاواخىه و همكاران نشان داد كه تجويز كيسول نعناع (Colpermin) به ها 9 بيمار بزركسال تحت

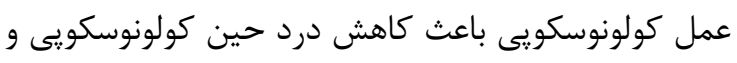
رضايتمندى بيمار مى شود [YV] كه با نتايج تحقيق حاضر

$$
\text { همسو مى باشد. }
$$

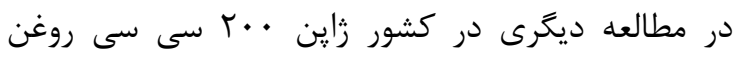
نعناع همراه آب و تويين توسط يك يمب دست دستى به كانال فرعى دستخاه كولونسكوٍ وارد شد. نتايج نشان داد تزريق

1-Liu

2-Merat

3 -Ford

4 -Goerge

5 -Shavakhi
نتايج مطالعه حاضر نشان داد كه تجويز قطره خوراكى

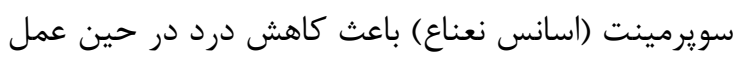

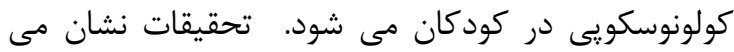
دهد كه كياه نعناع ريلكس كننده انقباض عضلانى است.

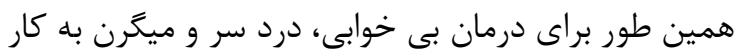

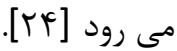
مطالعه فاضل نشان داد كه تجويز سويرمينت باعث كاهش

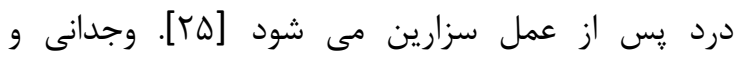

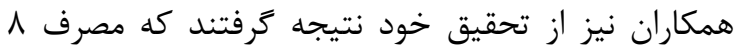
هفته عصاره نعناع باعث كاهش درد در بيماران مبتلا به

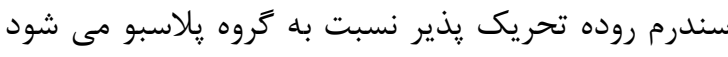


داخل لومن كولون باعث كاهش درد به مدت · r دقيقه در حين كولونسكويى مى شود [r/r)]

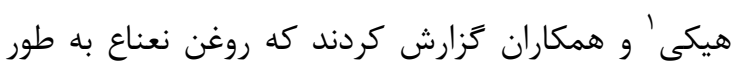

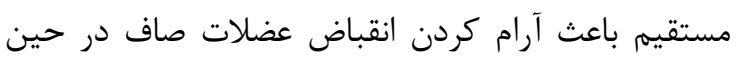

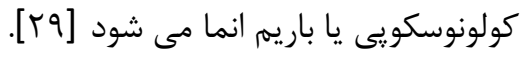

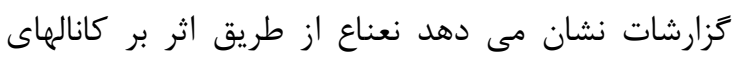

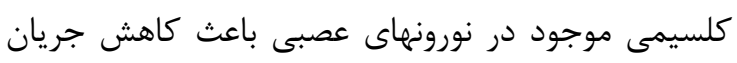

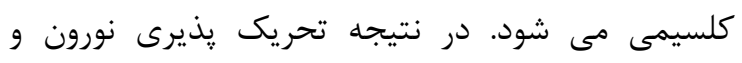

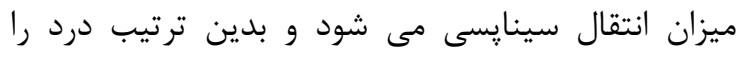
كاهش مى دهد [rك].

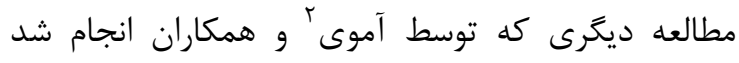

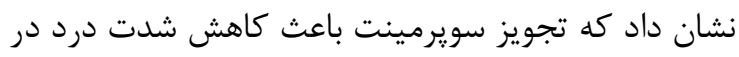

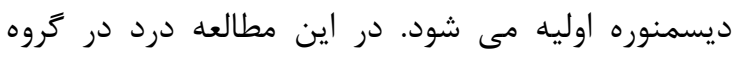

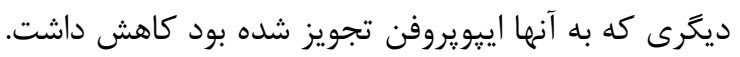

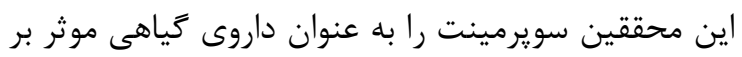

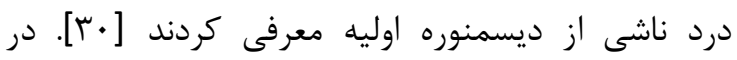

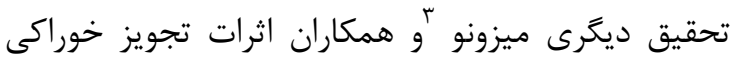

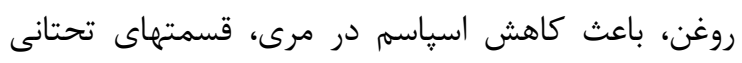

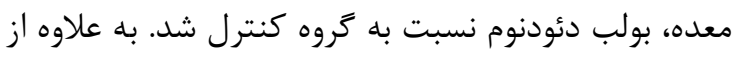

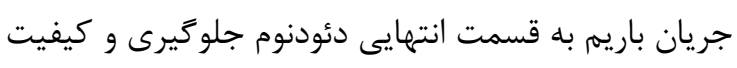

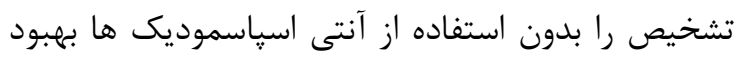

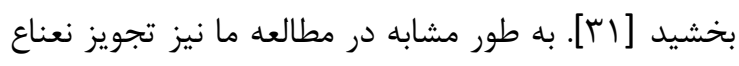
باعث كاهش اسياسم و درد حين كلونوسكويى شد. نتيجه كيرى

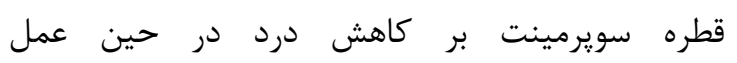
كولونسكويى كودكان تاثير مثبت دارد. تشكرو قدر دانى كولى كانى

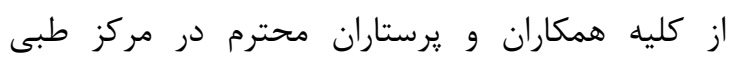

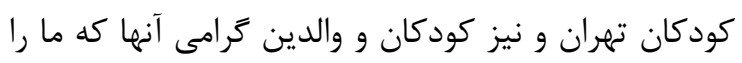
در انجام اين تحقيق صميمانه يارى نمودند، كمال تشكر و و

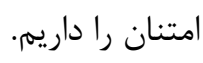




\section{References}

1. Crisp J Taylor C (2005), Potter \& Perry's Fundamental of Nursing, _2nd edition, Sydney, Mosby Co.

2. 2.Kim JT, Wajda M, Cuff G, Serota D, Schlame M, Axelrod DM, Guth AA, Bekker AY, Evaluation of aromatherapy in treating postoperative pain: pilot study. Pain Pract. 2006 Dec;6(4):273-7.

3. Howarth AL, Will aromatherapy be a useful treatment strategy for people with multiple sclerosis who experience pain? Complement Ther Nurs Midwifery 2002 Aug;8(3):138-41.

4. Zargari A, Medicinal Plants. Vol 4. Tehran:University Publications of Tehran, 1990: 28-38[Persian].

5. Vlietinck AJ, Vanden Berghe DA, Can ethnopharmacology contribute to the development of antiviral drugs? J Ethnopharmacol 1991; 32:141-53.

6. Bekhradi R, New treatment plant. Tehran: Islamic Propagation Office;2004.p.920 [Persian].

7. Trentin AP, Santose ARS, Miguel OG, Mechanisms Involved in The Antinociceptive Effect in Mice of The Hydroalcohlic Extract of Siphcamphylus Verticillatus, J Pharm Phrmacol 1997;49:567-72.

8. Fennerty M, Nsaid-Ralated Gasrointestional Injury: Evidence-Based Approach to Preventable Complication, Postgrad Med 2001:110(3):87-92.

9. Zeng J, Zhao DS, Wu B, A Study on Chemical Constituents in the Herb of Mentha Spicata, J Zhongguo Zhong Yaoza Zhi 2002;27(10):749-51.

10. Arumugam P, Ramamurthy P, Santhiya St, Antioxydant Activity Measured in Different Solvent Fraction Obtained from Mentha Spicata Linn:an Analysis by ABTS Decolorization Assay, Asia Pac J Clin Nutr 2006;15(1):119-24.

11. Tu T, Xu M, Dashwood R, Antimutagenic Activity of Spearmint, J Environ Mol Mutagen 2004;44(5):387-93.

12. Atta AT, Alkofahi A, Anti-Nociceptive and Anti-Inflammatory Effect of Some Jordanian Medicinal Plant Extracts,Journal of Ethnopharmacology 1998;60:117-124.

13. Atta AH, Alkofahia A, Anti-nociceptive and antiflammatory effect of some tordanian medicinal plant extracts, J Ethnopharmacol Boca 1998; pp: 117-24.
14. Hamthorn M, Ferrante J, Luchowski E, The Action of Peppermint Oil and Menthol on Calsium Channel Dependent Processes Intestinal, Neuronal and Cardiac Preparation, J Aliment Pharmacol Ther 1988;2(2):101-18.

15. Velag j, Studulaj j, Medical Plants, Translation by Zaman S, Tehran: Ghoghnus;2000. P.3. [Persian].

16. Abdolahi Kakrudi H. "Oregano Effect of postoperative nausea and vomiting in patients undergoing chemotherapy in Omid Hospital", MA thesis, Faculty of Nursing and Midwifery Mashhad University of Medical Sciences, 2000.

17. Ahmadiani A, Samanian S, Inhibition of acute and chronic pain with rhizome extracts of Elderberry in the rat.J of Physiology and Pharmacology 1987; 2(1):123-127.[persian]

18. Heidari R, Sharifi F, Orangi B, Salmani M, Analgesic effect of ethanol extracts of ginger and pepper, Tehran: Mani;2002.p.21[Persian]..

19. Liu JH, Chen GH, Yeh HZ, "et al”, Entericcoated peppermint oil capsule in the treatment of irritable bowel syndrome a prospective /randomized trial, J Gastrorentrol 1997; 32: $765-8$.

20. Merat S, Khalili S, Mostajabi P, Ghorbani A, Ansari R, Malekzadeh R, The effect of enteric-coated, delayed-release peppermint oil on irritable bowel syndrome, Dig Dis Sci. 2010 May;55(5):1385-90. doi: 10.1007/s10620-0090854-9. Epub 2009 Jun 9.

21. Ford AC, Talley NJ, Spiegel BM, FoxxOrenstein AE, Schiller L, Quigley EM, Moayyedi P, Effect of fibre, antispasmodics, and peppermint oil in the treatment of irritable bowel syndrome: systematic review and metaanalysis. BMJ, 2008 Nov 13;337:a2313. doi: 10.1136/bmj.a2313.

22. Goerg KJ, Spilker T, Effect of peppermint oil and caraway oil on gastrointestinal motility in healthy volunteers: a pharmacodynamic study using simultaneous determination of gastric and gall-bladder emptying and orocaecal transit time, Aliment Pharmacol Ther 2003 Feb;17(3):445-51.

23. Kingham JG, Peppermint oil and colon spasm, Lancet 1999; 98: 346.

24. Nafisi A, Properties of food and Beverages among Various nations over the Centuries and ages,Esfahan: Esfahan University of Medical Sciences, 1990[Persian].

25. Fazel N, Effect Supermint oil (peppermint oil) on pain after Cesarean. JBUMS Journal of 
Babol University of Medical Sciences 2003;25(1):28-33[Persian].

26. Vejdani R, Shalmani HR, Mir-Fattahi M, Sajed-Nia F, Abdollahi M, Zali MR, Mohammad Alizadeh AH, Bahari A, Amin G, The efficacy of an herbal medicine, Carmint, on the relief of abdominal pain and bloating in patients with irritable bowel syndrome: a pilot study, Dig Dis Sci. 2006 Aug;51(8):1501-7, Epub 2006 Jul 26[Persian].

27. Shavakhi A, Ardestani SK, Taki M, Goli M, Keshteli AH, Premedication withpeppermint oil capsules in colonoscopy: a double blind placebo-controlled randomized trial study, Acta Gastro-enterologica Belgica [2012, 75(3):349-353] [Persian].

28. Takayuki Asao, Erito Mochiki, Hideki Suzuki, Jun-ichi Nakamura, Isao Hirayama, Nobuhiro Morinaga, Hisanori Shoji, Yoshinori Shitara, Hiroyuki Kuwano, An easy method for the intraluminal administration of peppermint oil before colonoscopy and its effectiveness in reducing colonic spasm, Gastrointestinal
Endoscopy, Volume 53, Issue 2, February 2001, Pages 172-177.

29. Hiki N, Kurosaka H, Tatsutomi Y, Shimoyama S, Tsuji E, Kojima J, Shimizu N, Ono H, Hirooka T, Noguchi C, Peppermint oil reduces gastric spasm during upper endoscopy: a randomized, double-blind, double-dummy controlled trial, Gastrointest Endosc. 2003;57:475-482.

30. Amoi Roknabad M, Sarafraz N, Impact Supermint oil (peppermint extract) compared to ibuprofen in primary dysmenorrhea: a randomized clinical trial, $\mathrm{J}$ Ghom 2010:5(3):37-41[Persian].

31. Mizuno S, Kato K, Ono Y, Yano K, Kurosaka H, Takahashi A, Abeta H, Kushiro T, Miyamoto S, Kurihara R, Hiki N, Kaminishi M, Iwasaki A, Arakawa Y, Oral peppermint oil is a useful antispasmodic for double-contrast barium meal examination, J Gastroenterol Hepatol. 2012, 75(3):349-353. 
Original Article

\title{
Effect Supermint oil (peppermint oil) on children's pain during colonoscopy
}

\author{
Najaphi $M^{1}$, Motamed $F^{1}$, * Kiani $M A^{2}$, Khakshour $A^{3}$, Saeidi $M^{2,4}$, Jafari $S A^{2}$, Attai $P^{5}$, Ghayour \\ Mobarhan $\mathrm{M}^{6}$, Mohammadi $\mathrm{Sh}^{7}$
}

\footnotetext{
${ }^{1}$ Department of Pediatrics, Faculty of Medicine, Tehran University of Medical Science(TUMS), Tehran, Iran.

${ }^{2}$ Department of Pediatrics, Faculty of Medicine,Mashhad University of Medical Sciences (MUMS), Mashhad, Iran.

${ }^{3}$ Department of Pediatrics, Faculty of Medicine, North Khorasan University of Medical Sciences, Bojnurd, Iran.

${ }^{4}$ Students Research Committee, Faculty of Medicine,Mashhad University of Medical Sciences (MUMS), Mashhad, Iran.

${ }^{5}$ Department of Pediatrics, Faculty of Medicine, Kordestan University of Medical Sciences, Sanandaj, Iran.

${ }^{6}$ Biochemistry and Nutritional Research Center, Faculty of Medicine, Mashhad University of Medical Science(MUMS), Mashhad, Iran.

${ }^{7}$ Department of Anatomy, Faculty of Medicine, Mashhad University of Medical Science(MUMS), Mashhad, Iran.
}

*Corresponding Author:
Department of
Gastroenterology, Mashhad
University of Medical
Sciences, Mashhad, Iran.
E-mail:
kianiMD@yahoo.com

Submitted:2013 July 8

Revised:2013 Agu 3

Accepted: 2013 Sep 7

\begin{abstract}
Background \& Objectives: Pain during colonoscopy, especially in children, including the challenges faced by the medical team. The aim of study was investigation the analgesic effect Supermint oil (peppermint oil) on pain in children during colonoscopy.

Materials and Methods: In this clinical trial study, 101 children (7-14 years old) candidate colonoscopy were randomly divided into two groups, respectively. About half an hour before the colonoscopy case group $(n=51)$ was administrated oral drops Supermint oil (peppermint oil). Patients were filled a pediatric pain questionnaire. In control group $(n=50)$ filled a questionnaire without any administration. Data were analyzed using SPSS version 11.5 and (T-test and Paired sample t-test, Corraletion, Man withney).
\end{abstract}

Results: The mean value of pain, duration of colonoscopy in control group $(5 / 60+1 / 85)$ was significantly different from case group $(4 / 20 \pm 1 / 70)(p<0.05)$. Result showed the comparison of pain between two groups was significant, so in case group, the frequency of abdominal pain were two times at maximum, but in the control group for some patients were more than 3 times $(p<0.05)$. In the case group abdominal pain lasting less than 1 minute and the control group were between 1 to 3 minutes, and this difference was significant $(p<0.05)$.

Conclusion: We recommend using peppermint oil as a safe ,without complications and inexpensive pain medication during child colonoscopy.

Key words: peppermint -pain-colonoscopy-Supermint. 